\title{
Incidence of Aortic Regurgitation in Association with Type of Ventricular Septal Defects and its Immediate and Intermediate Outcome after Surgical Closure
}

Veena Kumari ${ }^{1}$, Abdul S. Shaikh ${ }^{1}$, Saad B. Zakai SBZ ${ }^{2}$, Naresh Kumar ${ }^{1}$, Sohail K. Bangash ${ }^{2}$, Najma Patel ${ }^{1}$

1. Paediatric Cardiology, National Institute of Cardiovascular Diseases, Karachi, PAK 2. Paediatric Cardiac Surgery, National Institute of Cardiovascular Diseases, Karachi, PAK

$\square$ Corresponding author: Veena Kumari, veenakumari77@yahoo.com

Disclosures can be found in Additional Information at the end of the article

\section{Abstract}

\section{Introduction}

Ventricular septal defect (VSD) is one of the more common congenital heart defects, and aortic regurgitation (AR) is its major complication if it remains unrepaired. We aim to determine the AR incidence in various types of VSD, its immediate and intermediate six to 12-month postVSD repair outcomes of AR.

\section{Methods}

We conducted a retrospective review of medical records of all children aged 18 years or younger who were diagnosed with single VSD at our institution from 2016 to 2018 . VSD was classified according to its location and relation to the tricuspid annulus and semilunar valve. AR severity grading was done according to the American Society of Echocardiography, and vena contracta width (VC) was taken as the main parameter for severity. We defined trivial-to-mild AR as VC width less than $0.3 \mathrm{~cm}$, moderate AR was $0.3-0.6 \mathrm{~cm}$ VC width, and severe AR was VC width of more than $0.6 \mathrm{~cm}$. Immediate and intermediate outcomes of surgical closure, such as residual VSD and AR, were observed.

\section{Results}

One hundred ninety patients with isolated single VSD were included in the study. Of those, 114 patients had perimembranous VSD (60.0\%), 64 patients had muscular VSD (33.7\%), and 12 patients had supracristal VSD (6.3\%). The median age of our study cohort was six months, with a male to female ratio of $1.3: 1$. Aortic valve prolapse $(28.9 \% ; n=55)$ and AR $(23.2 \% ; n=44)$ were the most common findings on echocardiographic evaluation of VSD patients. Most cases of VSD with AR had trivial-to-mild AR, (68.2\%; $n=30)$. AR was most commonly seen in supracristal VSD $(83.3 \%$; $n=10)$ followed by perimembranous VSD (28.9\%; $n=33)$. VSD closed spontaneously in 34 patients (17.9\%) and 98 patients (51.6\%) patients underwent surgery. Residual VSD after surgical closure was present in 57.1\% (56) and $17.3 \%$ (17) of the patients immediate postoperatively and six- to 12-month postoperative follow-up, respectively. Similarly, residual AR after surgical closure of VSD was present in 32.7\% (32) and 15.3\% (15) of the patients immediate postoperatively and six- to 12-month postoperative follow-up, respectively. 


\section{Conclusion}

The incidence of AR with VSD was very high in our study; AR was most commonly associated with supracristal VSD. After surgical repair, mild AR decreased with time. Early corrective surgery of VSD can prevent this complication and help improve outcomes.

Categories: Cardiology, Pediatrics

Keywords: aortic regurgitation, vsd, surgical vsd closure, residual vsd

\section{Introduction}

Of all congenital heart disease (CHD), ventricular septal defects (VSDs) are the most common form [1-2]. VSDs result from a deficiency or a failure of alignment or fusion of components of the ventricular septum during the embryological development of the heart [3].

The natural history of an untreated or undiagnosed VSD that does not spontaneously close is associated with several complications like hemodynamic disturbances, congested cardiac failure, growth failure, right ventricular or left ventricular outflow tract obstruction, aortic valve prolapse (AVP), and subsequent development of aortic regurgitation (AR) [4-5]. AR is the important and major complication, and the risk of AVP and AR progressively increases if VSD left untreated [4]. These factors ultimately increase the mortality associated with unrepaired VSD. Spontaneous VSD closure usually occurs in the first year of life [2]. Furthermore, the first two years of life are considered crucial in terms of early surgical correction, which leads to higher chances of complete recovery of left ventricular function. Given that these defects rarely close after age two, early and correct identification of the type and size of VSD is important for positive outcomes [5].

The incidence of CHD in Pakistan is highly underestimated due to the popular practices of home deliveries and quick discharge of neonates from hospital deliveries. VSDs are estimated to be the most common cardiac defects in Pakistan, responsible for $25 \%-45 \%$ of all congenital cardiac defects according to some hospital-based studies [6-9].

VSDs are divided into three types: perimembranous (pm), muscular, and doubly committed subarterial (DCSA)/Supracristal [10]. Although the development of complications from a VSD depends on its size, the type of defect also dictates its natural history. pm-VSDs are more common, but muscular VSDs have a better outcome; their spontaneous closure takes place earlier as compared to pm-VSDs. DCSA-VSDs have poor outcomes due to their association with the progressive development of AVP and AR [5,11-12].

Regarding the type of VSDs, the limited data from Pakistan show slightly contrasting results. One study showed DCSA as the least common type of VSD, and another study showed muscular VSDs as the least common; both, however, concluded pm-VSD as the most common [7]. AR is progressive, and the presence of even AVP or mild AR is an indication for surgery [13-14]. In our country, many VSDs remain uncorrected or present at a later age, so it would be interesting to see the incidence of AVP and AR in our patients along with the outcome after surgical VSD repair. These data may help to encourage physicians to correct VSD early to decrease the incidence of complications such as AVP and AR.

\section{Materials And Methods}

We retrospectively reviewed the medical records and echocardiographic findings of all patients aged 18 or younger with a single VSD diagnosis via transthoracic echocardiography at our institution from 2016 to 2018. Approval of the ethical review committee was obtained (ERC- 
27/2019). The study included children who had at least one presurgical echocardiographic study and two postsurgical studies (within 24 to 48 hours and six to 12 months postoperative). Children were excluded if they had complex congenital heart disease or multiple VSDs or VSD with any other associated CHD and if they died immediately postoperative. The study ultimately included 190 patients. VSDs were classified according to location and relation to the tricuspid annulus and semilunar valve, as described by Sutherland et al. [15]. Aortic valve prolapse (AVP) was diagnosed when a deformed aortic cusp pivoted from the crest of the interventricular septum, which is noticeable in a parasternal long-axis view [16].

AR severity grading was done according to the American Society of Echocardiography, and vena contracta width (VC) was taken as the main parameter for severity. AR was defined as trace-tomild if VC width was less than $0.3 \mathrm{~cm}$, moderate AR was defined as VC width of $0.3 \mathrm{~cm}$ to 0.6 $\mathrm{cm}$, and severe AR was defined as VC width more than $0.6 \mathrm{~cm}$ [17].

Statistical analysis was performed by using IBM SPSS Statistics for Windows, Version 21.0. (IBM Corp., Armonk, NY, US). Results were presented as mean and standard deviation for continuous variables (i.e., patient age and size of VSD) and frequency and percentage for categorical variables (i.e., gender, AR, type of VSD, and severity of AR). The chi-square test was applied, and a $\mathrm{p}$-value of $\leqslant 0.05$ was considered significant.

\section{Results}

pm-VSD was the most common type (60\%) in our study population. AVP was noted in 55 patients (28.9\%), while AR was noted in 44 (23.2\%) patients. Demographic characteristics of the patients, types of VSD, number of spontaneously closed VSDs, and number of patients who underwent surgery with residual VSD or AR are shown in Table 1. 


\section{Cureus}

\section{Demographic feature and outcomes}

Age in months (median and IQR)

Percent of males (n)

Mean VSD size \pm SD

Type of VSD

Perimembranous, conoventricular (n)

Supracristal / DCSA, conotruncal (n)

Muscular (n)

$\operatorname{AVP}(n)$

$\operatorname{AR}(n)$

Sign and symptoms of CHF ( $n$ )

Associated dysmorphic features/ syndrome (n)

Spontaneously closure (n)

No indication for surgery (n)

Underwent surgery $(n)$

Residual VSD ( $\mathrm{n}=98)$

Immediate postoperatively (n)

Within one year follow-up(n)

Residual AR [ $n=98]$

Immediate postoperatively (n)

Within one year follow-up (n) $n=190$

$6(3-20)$

$55.8 \%(106)$

$5.0 \mathrm{~mm} \pm 2.7 \mathrm{~mm}$

$60 \%(114)$

$6.3 \%(12)$

$33.7 \%(64)$

$28.9 \%(55)$

$23.2 \%(44)$

$51.1 \%(97)$

$18.9 \%(36)$

$17.9 \%(34)$

$30.5 \%(58)$

$51.6 \%(98)$

$57.1 \%(56)$

$17.3 \%(17)$

$32.7 \%(32)$

$15.3 \%(15)$

\section{TABLE 1: Demographic profile and postoperative outcomes of the study population}

Abbreviations: AR, aortic regurgitation; AVP, aortic valve prolapse; CHF, congestive heart failure; DCSA, doubly committed subarterial; VSD, ventricular septal defect; SD, standard deviation; IQR, interquartile range.

Patients with supracristal VSD had the highest incidence of AR $(83.3 \% ; \mathrm{n}=10 / 12)$, and patients with muscular VSD had the lowest incidence of AR $(1.6 \% ; \mathrm{n}=1 / 64)$, as shown in Table 2 . 


\section{Cureus}

\begin{tabular}{|c|c|c|c|c|}
\hline \multirow{2}{*}{ Type of VSD } & \multirow{2}{*}{$\mathbf{n}$} & \multicolumn{3}{|c|}{ Aortic regurgitation } \\
\hline & & Absent & Present & $p-$ Value ${ }^{a}$ \\
\hline Perimembranous & 114 & $71.1 \%(81)$ & $28.9 \%(33)$ & \multirow{3}{*}{$<0.001^{*}$} \\
\hline Supracristal & 12 & $16.1 \%(2)$ & $83.3 \%(10)$ & \\
\hline Muscular & 64 & $98.4 \%(63)$ & $1.6 \%(1)$ & \\
\hline
\end{tabular}

\section{TABLE 2: Frequency of aortic regurgitation according to the type of ventricular septal defect preoperatively}

Abbreviation: VSD, ventricular septal defect.

ap-value is based on chi-square test

*Significant at 5\%

Among the patients with preoperative AR, most of the patient had trivial-to-mild AR (68.2\%; $\mathrm{n}$ = 30), as shown in Table 3. Of the 190 total children, 98 patients (51.6\%) underwent surgery, and residual VSD was found in 56 patients $(57.1 \%)$ in the immediate postoperative period. The incidence of residual VSD reduced to $17.3 \%(n=17)$ after the one-year follow-up $(p \leqslant .001)$ as shown in Table 3. Immediate postoperative residual AR was observed in 32 children (32.7\%), a reduction from the preoperative frequency of $\mathrm{AR}(44.9 \% ; \mathrm{n}=44 ; \mathrm{p}=0.079)$. At the one-year follow-up evaluation, the incidence was further reduced $(15.3 \% ; n=15 ; p \leqslant .001)$. 


\section{Cureus}

\begin{tabular}{|l|lll|}
\hline Outcomes & Preoperative status & Immediate postoperatively & Within one year postoperatively \\
\hline $\mathrm{N}$ & 98 & 98 & 98 \\
Residual VSD $(\mathrm{n})$ & - & $57.1 \%(56)$ & $17.3 \%(17)$ \\
*Size of Residual VSD & & \\
$<2 \mathrm{~mm}(\mathrm{n})$ & - & $69.6 \%(39)$ & $47.1 \%(8)$ \\
$>2 \mathrm{~mm}(\mathrm{n})$ & - & $30.4 \%(17)$ & $52.9 \%(9)$ \\
AR $(\mathrm{n})$ & $44.9 \%(44)$ & $32.7 \%(32)$ & $15.3 \%(15)$ \\
$*{ }^{*}$ AR Severity Grading & & $66.7 \%(10)$ \\
Trivial-to-Mild $(\mathrm{n})$ & $68.2 \%(30)$ & $71.9 \%(23)$ & $33.3 \%(5)$ \\
Moderate $(\mathrm{n})$ & $25 \%(11)$ & $25 \%(8)$ & $0 \%(0)$ \\
Severe $(\mathrm{n})$ & $6.8 \%(3)$ & $3.1 \%(1)$ & \\
\hline
\end{tabular}

TABLE 3: Residual ventricular septal defect, aortic regurgitation and its severity grading, preoperatively, immediate postoperatively, and within one-year follow-up in patients receiving surgical ventricular septal defect closure

Abbreviations: AR, aortic regurgitation; VSD, ventricular septal defect.

${ }^{*}$ Based on patients with residual VSD

${ }^{* *}$ Based on patients with AR

AR severity also improved; of the 30 children who had trivial-to-mild AR preoperatively, 23 retained it in the immediate postoperative period, and 10 still had it at the six- to 12-month follow-up. Of the 11 children with moderate AR who needed aortic valve repair, eight children still had AR in the immediate postoperative period, and five had AR at the six- to twelve-month follow-up. All patients with severe AR underwent aortic valve replacement. One of them had severe AR as an immediate complication due to paravalvular leakage for which reoperation was performed. None had severe AR at the 12-month follow-up (Table 3).

\section{Discussion}

Percentage of spontaneous closure of VSDs is variable and depends upon the age of the patient, the type and size of the VSD. The literature indicates a wide range of $8.8 \%$ to $85 \%$ of cases spontaneously close $[2,18]$. In our study, spontaneous closure occurred in $17.9 \%$ of cases. The natural history of VSD shows that spontaneous closure rarely occurs after the first two years of life and is associated with many complications, the most important of which is AR $[5,7]$. Once AR develops, its progressive nature is associated with significant mortality, and it becomes highly unlikely that VSD will close spontaneously. This natural history suggests early surgical intervention [19-20]. 
incidence of VSD, frequency of its types, early repair, and outcomes [6-8]. In our study, pm-VSD was the most common (60\%), which aligns with several Western studies [20-21]. Eroglu et al. reported an incidence of pm-VSD of 65\% and DCSA of 12\% [20]. Aziz et al. reported a pm-VSD incidence of 92\%, whereas DCSA-VSD incidence was only 7\% [21]. Studies from Japan and China report the incidence of DCSA-VSD to be $30 \%$ [22].

According to our findings, muscular VSD was the second-most common with a frequency of $34 \%$, while DCSA was the least common at $6 \%$. The median age of patients in our study was six months, which is similar to other studies in Pakistan by Aziz et al. [21], Kazmi et al. [7], and Chaudhry et al. [23].

A subset of patients with VSD develop AR; these may be pm or DCSA. The literature has shown that AR implicates DCSA more than pm-VSD. The mechanisms responsible for AVP are a lack of leaflet structural support due to VSD, abnormalities in commissural suspension, a lack of oppositional forces, a lack of continuity between the aortic media and annulus, and the venturi effect [14]. Tohyama et al. reported that AVP developed in 69\% of cases with DCSA-VSD [16]. Most of the literature from Western countries report a higher incidence of AR with DCSA. However, data published from Pakistan show a higher incidence of AR in cases of pm-VSD [7,23]. Contrary to local studies, our population showed a higher incidence of AR in DCSA-VSD (83.3\%) than pm-VSD (28.9\%; $\mathrm{p}<0.001)$.

One of the indications for the closure of VSD in both DCSA and pm-VSD is the presence of AR and AVP. Even if the AR is trivial, it is still progressive. Lun et al. proposed that all DSCA-VSD 》 $5 \mathrm{~mm}$ should be closed regardless of the development of AVP or AR [24]. Closure of VSD before the development of cusp deformation will prevent the development of AR. The incidence of postoperative residual VSD varies according to the type and size of VSD being repaired. Malaligned and muscular VSD repair may produce higher residual rates [25-26]. SayadpourZanjani et al. reported postoperative residual VSD in $56 \%$ of cases [27]. Residual shunts may result in left ventricular volume overload, pulmonary arterial hypertension, and risk of bacterial endocarditis. Residual shunts have an impact on the postoperative recovery period and morbidity of the patient in addition to the financial and psychological status of the parents or guardians. Patients with residual VSDs need continued endocarditis prophylaxis and periodic follow-up to determine the need for repeated surgery. A Qp/Qs $>1.5: 1$ is an indication for reintervention [25-26,28].

Ninety-eight (51.6\%) patients in our study underwent surgical closure, and 56 (57.1\%) had a residual VSD immediately following the procedure. Of those, 39 cases (69.6\%) of residual VSD closed spontaneously within one year and remained patent in 17 (30.4\%) patients. Bol-Raap et al. [29] reported spontaneous closure of residual VSDs in 51\% during the follow-up period of 3.9 years; they describe a high rate of spontaneous closure if the residual shunt is small [29]. The same trend was observed in our study, as children who had residual defects $<2 \mathrm{~mm}$ had a high rate of spontaneous closure within one year postoperatively (31/39; 80\%) compared to those with defects $>2 \mathrm{~mm}(8 / 17 ; 47 \%$; $=0.028)$.

The reduced AR due to surgical valve repair we noted in our study signifies the beneficial effects of timely surgery on chances of complete resolution of AR. AR resolves or improves in up to $84 \%$ of patients postoperatively, and younger patients tend to experience better results $[22,30]$.

Our study was limited by its retrospective nature, and we did not review the original echocardiogram findings. Our study was also limited in that we used a short follow-up period of one year. 


\section{Conclusions}

While pm-VSD is the most common type of VSD, DCSA/supracristal is most important due to its association with the development of AR. Postoperatively, AR decreases in severity and may completely disappear. Early surgical correction is advisable to prevent the occurrence and progression of AR to reduce morbidity and mortality associated with VSD complications.

\section{Additional Information \\ Disclosures}

Human subjects: Consent was obtained by all participants in this study. National Institute of Cardiovascular Diseases Karachi issued approval ERC-27/2019. Approval of the ethical review committee of the National Institute of Cardiovascular Diseases Karachi was obtained (ERC27/2019). Animal subjects: All authors have confirmed that this study did not involve animal subjects or tissue. Conflicts of interest: In compliance with the ICMJE uniform disclosure form, all authors declare the following: Payment/services info: All authors have declared that no financial support was received from any organization for the submitted work. Financial relationships: All authors have declared that they have no financial relationships at present or within the previous three years with any organizations that might have an interest in the submitted work. Other relationships: All authors have declared that there are no other relationships or activities that could appear to have influenced the submitted work.

\section{References}

1. Sands AJ, Casey FA, Craig BG, Dornan JC, Rogers J, Mulholland HC: Incidence and risk factors for ventricular septal defect in "low risk" neonates. Arch Dis Child Fetal Neonatal Ed. 1999, 81:61-63. 10.1136/fn.81.1.F61

2. Hoffman JI, Kaplan S: The incidence of congenital heart disease . J Am Coll Cardiol. 2002, 39:1890-1900. 10.1016/S0735-1097(02)01886-7

3. Rhodes LA, Keane JF, Keane JP, Fellows KE, Jonas RA, Castaneda AR, Nadas AS: Long followup (to 43 years) of ventricular septal defect with audible aortic regurgitation. Am J Cardiol. 1990, 66:340-345. 10.1016/0002-9149(90)90846-S

4. Lue HC, Sung TC, Hou SH, Wu MH, Cheng SJ, Chu SH, Hung CR: Ventricular septal defect in Chinese with aortic valve prolapse and aortic regurgitation. Heart Vessels. 1986, 2:111-116. 10.1007/BF02059965

5. Hrahsheh AS, Hijazi IS: Natural and modified history of ventricular septal defects in infants . Pak J Med Sci. 2006, 22:136-140.

6. Rahim F: Pattern of congenital heart diseases in children at tertiary care center in Peshawar . Pak J Med Sci. 2003, 19:19-22.

7. Kazmi U, Sadiq M, Hyder SN: Pattern of ventricular septal defects and associated complications. J Coll Physicians Surg Pak. 2009, 19:342-345.

8. Malik S: Frequency of cardiac defects among children at echocardiography center in a teaching hospital. Pak J Med Sci. 2009, 25:712-717.

9. Aman W, Sherin A, Hafizullah M: Frequency of congenital heart diseases in patients under the age of twelve years at Lady Reading Hospital Peshawar. J Postgrad Med Inst. 2011, 20:6469.

10. Soto B, Becker AE, Moulaert AJ, Lie JT, Anderson RH: Classification of ventricular septal defects. Br Heart J. 1980, 43:332-343. 10.1136/hrt.43.3.332

11. Miyake T, Shinohara T, Nakamura Y, Fukuda T, Tasato H, Toyohara K, Tanihira Y: Spontaneous closure of ventricular septal defects followed up from $<3$ months of age . Pediatr Int. 2004, 46:135-140. 10.1046/j.1442-200x.2004.01858.x

12. Kobayashi J, Koike K, Senzaki H, et al.: Correlation of anatomic and hemodynamic features with aortic valve leaflet deformity in doubly committed subarterial ventricular septal defect. Heart Vessels. 1999, 14:240-245. 10.1007/BF01747853

13. Rathore KS: Aortic regurgitation with ventricular septal defect in the young. Asian Cardiovasc Thorac Ann. 2006, 14:93-97. 10.1177/021849230601400202 
14. Tweddell JS, Pelech AN, Frommelt PC: Ventricular septal defect and aortic valve regurgitation: pathophysiology and indications for surgery. Semin Thorac Cardiovasc Surg Pediatr Card Surg Annu. 2006, 9:147-152. 10.1053/j.pcsu.2006.02.020

15. Sutherland GR, Godman MJ, Smallhorn JF, Guiterras P, Anderson RH, Hunter S: Ventricular septal defects. Two dimensional echocardiographic and morphological correlations. Br Heart J. 1982, 47:316-328. 10.1136/hrt.47.4.316

16. Tohyama K, Satomi G, Momma K: Aortic valve prolapse and aortic regurgitation associated with subpulmonic ventricular septal defect. Am J Cardiol. 1997, 79:1285-1289. 10.1016/S00029149(97)00105-7

17. Zoghbi WA, Enriquez-Sarano M, Foster E, et al.: Recommendations for evaluation of the severity of native valvular regurgitation with two-dimensional and Doppler echocardiography. J Am Soc Echocardiogr. 2003, 16:777-802. 10.1016/S0894-7317(03)00335-3

18. Saxena A, Tandon R, Shrivastava S: Clinical course of isolated ventricular septal defect: an Indian experience. Indian J Pediatr. 1993, 60:777-782. 10.1007/BF02751046

19. Ammash NM, Warnes CA: Ventricular septal defects in adults . Ann Intern Med. 2001, 135:812-824. 10.7326/0003-4819-135-9-200111060-00011

20. Eroglu AG, Oztunc F, Saltik L, Dedeoglu S, Bakari S, Ahunbay G: Aortic valve prolapse and aortic regurgitation in patients with ventricular septal defect. Pediatr Cardiol. 2003, 24:36-39. 10.1007/s00246-002-1423-6

21. Aziz K: Incidence of heart disease in children at the National Institute of Cardiovascular Diseases. J Pak Med Assoc. 1984, 34:300-305.

22. Sim EK, Grignani RT, Wong ML, et al.: Outcome of surgical closure of doubly committed subarterial ventricular septal defect. Ann Thorac Surg. 1999, 67:736-738. 10.1016/s00034975(98)01256-9

23. Chaudhry TA, Younas M, Baig A: Ventricular septal defect and associated complications . J Pak Med Assoc. 2011, 61:1001-1004.

24. Lun KS, Li H, Leung MP, Chau AK, Yung TC, Chiu CS, Cheung YF: Analysis of indications for surgical closure of subarterial ventricular septal defect without associated aortic cusp prolapse and aortic regurgitation. Am J Cardiol. 2001, 87:1266-1270. 10.1016/S0002-9149(01)01517-X

25. Pedra CA, Pontes JS, Pedra SR, et al.: Percutaneous closure of postoperative and posttraumatic ventricular septal defects. J Invasive Cardiol. 2007, 19:491-495.

26. Zhang B, Liang J, Zheng X, et al.: Transcatheter closure of postoperative residual ventricular septal defects using amplatzer-type perimembranous VSD occluders. J Invasive Cardiol. 2013, 25:402-405.

27. Sayadpour-Zanjani K, Aarabi-Moghadam M: Residual defects after surgical repair of ventricular septal defects in children: incidence, risk factors, and follow-up. Acta Medica Iranica. 2008, 46:495-500.

28. Otterstad JE, Erikssen J, Froysaker T, Simonsen S: Long term results after operative treatment of isolated ventricular septal defect in adolescents and adults. Acta Med Scand Suppl. 1986, 708:1-39. 10.1111/j.0954-6820.1986.tb18124.x

29. Bol-Raap G, Weerheim J, Kappetein AP, Witsenburg M, Bogers AJ: Follow-up after surgical closure of congenital ventricular septal defect. Eur J Cardiothorac Surg. 2003, 24:511-515. 10.1016/S1010-7940(03)00430-5

30. Cheung YF, Chiu CS, Yung TC, Chau AK: Impact of preoperative aortic cusp prolapse on longterm outcome after surgical closure of subarterial ventricular septal defect. Ann Thorac Surg. 2002, 73:622-627. 10.1016/S0003-4975(01)03393-8 